Iranica Journal of Energy \& Environment 2 (3): 250-257, 2011

ISSN 2079-2115

IJEE an Official Peer Reviewed Journal of Babol Noshirvani University of Technology

doi: 10.5829/idosi.ijee.2011.02.03.1837

\title{
Isotherm and Kinetics of Fe(II) Adsorption onto Chitosan in a Batch Process
}

\author{
${ }^{1}$ Hamideh Radnia, ${ }^{2}$ Ali Asghar Ghoreyshi and ${ }^{3}$ Habibollah Younesi \\ ${ }^{1,2}$ Department of Chemical Engineering Babol Noshirvani University of Technology, Babol, Iran \\ ${ }^{3}$ Department of Environmental Science, \\ Faculty of Natural Resources and Marine Science, Tarbiat Modares University, Noor, Iran
}

(Received: June 29, 2011; Accepted: August 20, 2011)

\begin{abstract}
In this study removal of $\mathrm{Fe}(\mathrm{II})$ by chitosan adsorbent was experimentally investigated in a batch system. The adsorbent dose and $\mathrm{pH}$ of the metal solution was fixed at $0.15 \mathrm{~g}$ and 4 , respectively. Adsorption experiments were carried out at initial concentration range of $10-50 \mathrm{mg} 1 \mathrm{G}$ at $20^{\circ} \mathrm{C}$. Equilibrium studies showed that experimental data were well fitted to Langmuir-Freundlich isotherm model. Linear and non-linear forms of pseudo-first-order and pseudo-second-order kinetic models were employed to describe the kinetic adsorption processes. The model parameters were confidently recovered. The kinetics followed the non-linear form of pseudo-first-order model which represents adsorption of $\mathrm{Fe}(\mathrm{II})$ on chitosan takes place through a physical process. The examination of kinetic data also revealed that the adsorption rate was dominated by intra-particle diffusion mechanism.
\end{abstract}

Key words: Chitosan \% Intraparticle diffusion \% Iron removal \% Isotherm models \% Pseudo-first-order $\%$ Pseudo-second-order

\section{INTRODUCTION}

Contamination of water by heavy metal is rapidly increasing in recent years due to extensive industrial and agricultural activities. Besides due to the pollution of environment by these materials, they have harmful effects on human body. Iron can be found in the wastewater streams in large amounts due to its extensive application in many different industries. Although micronutrients are essential for animals and plants, but they become very toxic at high concentrations $[1,2]$. Different methods have been used to remove iron from aqueous solutions such as Electrocoagulation[3], ion exchange [4], precipitation [5], extraction [6], membrane technologies [7], adsorption [8], etc. Cost, complexity and efficiency are important factors that affect selection of method for eliminating metal ions from water and waste water [9]. Adsorption technology has been considered as an economical, efficient and promising technology in wastewater treatment for removal of metal ions [10]. Choosing a proper adsorbent plays an important role in the efficiency of adsorption process. Many new type or traditional adsorbents have been tested in different conditions for this purpose [11, 12]. Chitosan is an effective natural macromolecule adsorbent [13]. It has a great tendency to eliminat metal ions due to large number of carboxylic and amino groups in its structure [14]. Chitosan and its derevetives have been used extensively in adsorption of heavy metals such as Fe (III), $\mathrm{Cu}$ (II) and $\mathrm{Pb}$ (II) [1], As (III) [15], Hg (II)[16], Co(II) and $\mathrm{Ni}(\mathrm{II})$ [17].

The main objective of the present study was to compare different kinetic models for describing the removal of $\mathrm{Fe}$ (II) by chitosan to investigate the adsorption mechanism. Also equilibrium data were analyzed in terms of different isotherm models and model parameters were recovered using a nonlinear fit of experimental data to the model equation.

\section{MATERIALS AND METHODS}

Materials: Chitosan with minimum 85\% deacetylation was purchased from Sigma-Aldrich (USA). All other chemicals used in this study were purchased from Merk (Germany).

Corresponding Author: Ali Asghar Ghoreyshi, Chemical Engineering Department,

Babol Noshirvani University of Technology, Babol, Iran.

Tel: +981113234204, Fax: +981113234201, E-mail: aa_ghoreyshi@nit.ac.ir. 
All reagents were analytic grade and used without further purification. Stock solution of $1000 \mathrm{mg} 1 \mathrm{G}$ of Fe(II) ions was prepared using crystallic heptahydrate ferrous sulfate salt. The stock solution was diluted to give the appropriate concentrations when necessary. Distilled water was used to prepare all the solutions.

Batch Experiments: Batch adsorption experiments were conducted in $250 \mathrm{ml}$ beakers with $100 \mathrm{ml}$ of iron solution. The mixture was equilibrated with chitosan at $180 \mathrm{rpm}$ in incubator shaker (model KS 4000i control, IKA) for 240 min. All experiments were conducted at $20^{\circ} \mathrm{C}$. Equilibrium studies were carried out by mixing $0.15 \mathrm{~g}$ of sorbent with solutions at $\mathrm{pH} 4$. Initial concentrations of metal solution varied from 10 to $50 \mathrm{mg} 1 \mathrm{G}$. Samples were taken at fixed time intervals to determine solution concentration. The samples were filtered with 0.45 ìm syringe filter to remove the adsorbent. Iron concentrations in the filtrates were analyzed by using a UV-Vis Spectrophotometer (model 2100 SERIES, UNICO), at $8_{\max }=425 \mathrm{~nm}$, according to the 5-sulfosalicylic acid (SSA) method [18].

The amount of metal ion adsorbed by chitosan was calculated according to the following equation [19]:

$$
q_{e}=\frac{C_{0} V_{0}-C_{e} V_{e}}{m}
$$

Where $\mathrm{q}$ is the concentration of $\mathrm{Fe}(\mathrm{II})$ in solid phase which is known as metal uptake capacity ( $\mathrm{mg} \mathrm{gG}$ ), $\mathrm{C}_{0}$ and $\mathrm{C}_{\mathrm{e}}$ are the initial and final metal concentrations (mg lG), $V_{0}$ and $\mathrm{V}_{\mathrm{e}}$ denotes the initial and final volume (l) respectively and finally $\mathrm{m}$ represents the mass of used adsorbent $(\mathrm{g})$.

\section{RESULT AND DISSCUSION}

Adsorption Isotherms: The experimental adsorption isotherm is a plot that shows the amount of equilibrium uptake versus the concentration of ion in the solution at the equilibrium state. This was obtained at different temperatures by changing initial Fe (II) concentration from 10 to $50 \mathrm{mg} 1 \mathrm{G}$.

It was observed that the ferrous ion adsorption capacity increased with increasing its concentration. In fact at higher initial concentration, available adsorption sites would be surrounded by more metal ions, therefore metal ions not only adsorbed in a monolayer at the outer interface of chitosan, but also it diffuses within chitosan particles. As a result, the sorption of ions would be carried out more sufficiently. This is a common observed phenomenon refered ferequently in adsorption literature $[20,21]$.
Equilibrium adsorption data were correlated with Langmuir, Freundlich and Langmuir-Freundlich isotherms. Langmuir model is a widely used model in adsorption. The basic idea behind this model is the coverage of the surface by a monomolecular layer. This model is determined as:

$$
q_{e}=\frac{q_{m} k_{L} C_{e}}{1+k_{L} C_{e}}
$$

Equation (3) represents Freundlich isotherm which is used for the adsorption on a heterogeneous surface with uniform energy:

$$
q_{e}=k_{F} C_{e}^{1 / n}
$$

Langmuir-Freundlich model is a three parameter model expressed by equation (4). This model can be used in the case of failure of the two-parameter isotherm models in describing the adsorption data [22].

$$
q_{e}=\frac{q_{m}\left(k_{L . F} C_{e}\right)^{b}}{1+\left(k_{L . F} C_{e}\right)^{b}}
$$

Where $\mathrm{q}_{\mathrm{e}}$ is the amount of metal adsorbed per unit weight of adsorbent at equilibrium ( $\mathrm{mg} \mathrm{gG}$ ), $\mathrm{C}_{\mathrm{e}}$ is the equilibrium metal concentration in solution ( $\mathrm{mg} \mathrm{lG}), \mathrm{q}_{\mathrm{m}}$ is the maximum uptake of adsorbate $(\mathrm{mg} g \mathrm{~g}), \mathrm{k}_{\mathrm{L}}$ and $\mathrm{k}_{\mathrm{F}}$ and $\mathrm{k}_{\mathrm{L} . \mathrm{F}}$ are the Langmuir, Freundlich and Langmuir-Freundlich equilibrium constants, respectively. $1 / \mathrm{n}$ is heterogeneity coefficient and b is a coefficient in Langmuir-Freundlich model.

As it can be seen in Fig. 1., all three models can fit experimental data well.

The model parameters are listed in Table 1. According to regression coefficient, data exhibit the best fit to the Langmuir-Freundlich model. Values of $1 / \mathrm{n}$ parameter in Freundlich model lie between 0 and 1 indicating favorable adsorption.

The equilibrium constant of the Langmuir isotherm model can be expressed in terms of a dimensionless separation factor $\left(R_{L}\right)$. This factor is used to predict the favorability of adsorption process. $R_{L}$ is determined as follows:

$$
R_{L}=\frac{1}{\left(1+k_{L} C_{i}\right)}
$$

These values indicate the shape of the isotherm to be either unfavorable $\left(R_{L}>1\right)$, linear $\left(R_{L}=1\right)$, favorable $\left(0<R_{L}<1\right)$ or irreversible $\left(R_{L}=0\right)$. The values of $R_{L}$ obtained for adsorption of Fe (II) onto chitosan is shown in Table 1. All the values of $R_{L}$ lie at range 0-1, indicating favorable adsorption of $\mathrm{Fe}$ (II) ions onto chitosan. 
Table 1: Adsorption isotherm constants for Fe(II) ions adsorbed by chitosan

\begin{tabular}{|c|c|c|c|c|c|c|c|c|c|c|}
\hline \multicolumn{4}{|c|}{ Langmuir } & \multicolumn{3}{|c|}{ Freundlich } & \multicolumn{4}{|c|}{ Langmuir-Freundlich } \\
\hline $\mathrm{k}_{\mathrm{L}}$ & $\mathrm{q}_{\mathrm{m}}$ & $\mathrm{R}^{2}$ & $\mathrm{R}_{\mathrm{L}}$ & $\mathrm{k}_{\mathrm{F}}$ & $\mathrm{n}$ & $\mathrm{R}^{2}$ & $\mathrm{k}_{\mathrm{L} . \mathrm{F}}$ & $\mathrm{q}_{\mathrm{m}}$ & $\mathrm{b}$ & $\mathrm{R}^{2}$ \\
\hline 0.1574 & 49.40 & 0.9953 & $0.11-0.38$ & 8.0027 & 1.66 & 0.9955 & 0.0554 & 80.27 & 0.78 & 0.9972 \\
\hline
\end{tabular}

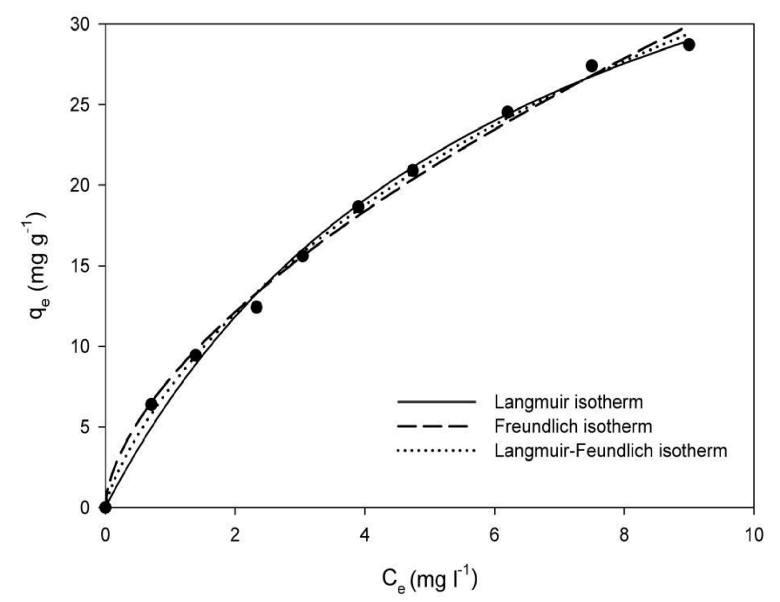

Fig. 1: Sorption isotherms of $\mathrm{Fe}(\mathrm{II})$ onto chitosan fitted to the Langmuir ,Freundlich and Langmuir Freundlich models at $20^{\circ} \mathrm{C}$.

Adsorption Kinetics: Kinetics study is an important part of researches in adsorption area because the mechanism of the process can be realized by kinetic constants. Knowledge about kinetic parameters provides valuable insight into the reaction pathway. As well the rate of adsorption which controls the resistance time is determined by kinetics [23]. In the present study,three different kinetic models have been used to fit the experimental rate data.

Pseudo-first-order Kinteic Model: The pseudo-first-order rate expression of Lagergren is a widely used kinetic model for adsorption data analysis. This kinetic model is used for reversible reaction with an equilibrium being established between liquid and solid phases [24]. it is represented by [25],

$$
\frac{d q}{d t}=k_{1}\left(q_{e}-q\right)
$$

Integrating Eq. (6) for the boundary conditions $t=0$ to $t=t$ and $q=0$ to $q=q_{t}$, results to the following Eq. ,

$$
\ln \frac{\left(q_{e}-q_{t}\right)}{q_{e}}=-k_{1} t
$$

Which may be rearranged to form,

$$
q_{t}=q_{e}\left(1-e^{-k_{1} t}\right)
$$

Where $q_{t}$ is the metal uptake capacity ( $\mathrm{mg} \mathrm{gG}$ ) at any time $\mathrm{t}, q_{e}$ denotes the metal uptake capacity (mg $\mathrm{gG}$ ) at equilibrium and $k_{1}(\operatorname{minG})$ is the the observed rate constant of pseudo-first-order kinetic model. Azizian [26] reported that $k_{1}$ is not the intrinsic adsorption rate constant which was mistakenly reported in the literature. He explained that it is a combination of adsorption $\left(k_{a}\right)$ and desorption $\left(k_{d}\right)$ rate constants.

$\mathrm{Eq}(8)$ may also be rearranged to obtain a linear form,

$$
\log \left(q_{e}-q_{t}\right)=\log q_{e}-\frac{k_{1}}{2.303} t
$$

$\mathrm{k}_{1}$ and $\mathrm{q}_{\mathrm{e}}$ values will be obtained by plotting $\log \left(\mathrm{q}_{\mathrm{e}}-\mathrm{q}_{\mathrm{t}}\right)$ versus $t$. It is obvious that in the absence of

\begin{tabular}{|c|c|c|c|c|c|c|c|}
\hline \multirow[b]{2}{*}{$\mathrm{C}_{0}(\mathrm{mg} \mathrm{lG})$} & \multirow[b]{2}{*}{$\mathrm{q}_{\mathrm{e}, \exp }(\mathrm{mg} \mathrm{gG})$} & \multicolumn{3}{|l|}{ Linear form } & \multicolumn{3}{|c|}{ Non-linear form } \\
\hline & & $\mathrm{q}_{\mathrm{e}}(\mathrm{mg} \mathrm{gG})$ & $\mathrm{k}_{1}(\min \mathrm{G})$ & $\mathrm{R}^{2}$ & $\mathrm{q}_{\mathrm{e}}(\mathrm{mg} \mathrm{gG})$ & $\mathrm{k}_{1}(\min G)$ & $\mathrm{R}^{2}$ \\
\hline 10 & 6.39 & 4.720630 & 0.029478 & 0.9592 & 6.2901 & 0.0442 & 0.9883 \\
\hline 15 & 9.43 & 9.774623 & 0.038000 & 0.9947 & 9.6936 & 0.0334 & 0.9976 \\
\hline 20 & 12.41 & 14.38467 & 0.041454 & 0.9792 & 12.8161 & 0.0316 & 0.9959 \\
\hline 25 & 15.59 & 13.39368 & 0.029018 & 0.9796 & 15.6309 & 0.0347 & 0.9934 \\
\hline 30 & 18.64 & 18.38654 & 0.026485 & 0.9798 & 19.0641 & 0.0251 & 0.9939 \\
\hline 35 & 20.9 & 20.59207 & 0.019576 & 0.9774 & 21.8722 & 0.0177 & 0.9676 \\
\hline 40 & 24.51 & 23.99938 & 0.027636 & 0.9927 & 24.559 & 0.0285 & 0.9878 \\
\hline 45 & 27.4 & 27.37789 & 0.023951 & 0.9957 & 27.9328 & 0.0231 & 0.9969 \\
\hline 50 & 28.71 & 28.26181 & 0.016812 & 0.9937 & 29.7977 & 0.0162 & 0.9955 \\
\hline
\end{tabular}
experimentally determined $\mathrm{q}_{\mathrm{e}}$ values, Eq. (9) may not be applicable [27].

Table 2: Pseudo-first-order kinetic parameters for Fe(II) ions adsorption by chitosan 

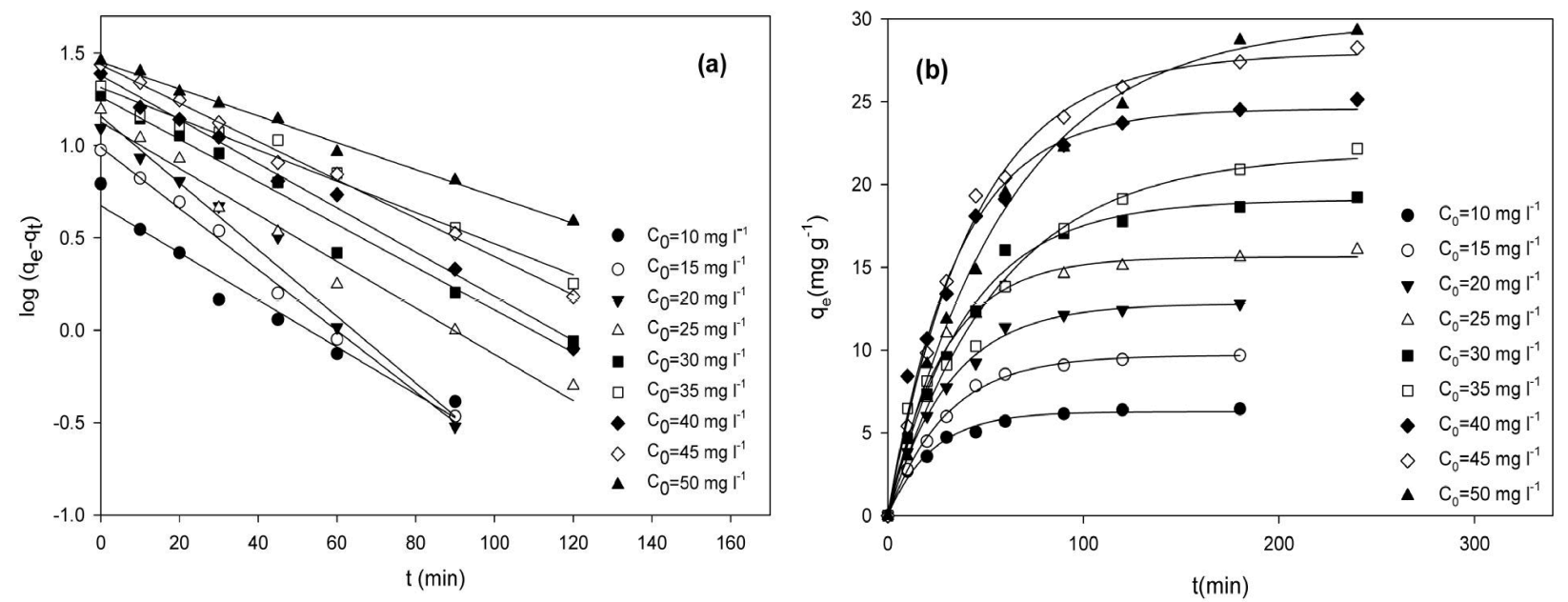

Fig. 2: Pseudo-first-order kinetic model of Fe(II) adsorption on chitosan, (a) linear and (b) non-linear form.

Fig. 2. shows kinetic data fitted to Eqs. (8) and (9).

Model parameters are presented in Table 2. Non-linear form of pseudo-first-order kinetic model gives a better fit to the experimental data due to higher correlation coefficient. Also equilibrium sorption capacity predicted by non-linear form is more reasonable almost in all different concentrations and it is in agreement with the experimental $\mathrm{q}_{\mathrm{e}}$ values.

Pseudo-Second-Order Kinteic Model: Most of the sorption systems followed a pseudo-secondorder kinetic model which is based on the assumption that the rate-limiting factor may be chemisorptions [24]. In chemisorptions (chemical adsorption), the metal ions stick to the adsorbent surface by forming a chemical (usually covalent) bond and tend to find sites that maximize their coordination number with the surface [28]. In other words chemisorption involves valence forces through sharing or exchange of electrons between the metal ions and the adsorbent. The rate law for this system is expressed as [25],

$$
\frac{d q}{d t}=k_{2}\left(q_{e}-q\right)^{2}
$$

Integrating this for the boundary conditions $t=0$ to $t=t$ and $q=0$ to $q=q_{t}$, gives,

$$
\frac{1}{\left(q_{e}-q_{t}\right)}=\frac{1}{q_{e}}+k_{2} t
$$

Eq. (11) may be rearranged to form following Eq.,

$$
q_{t}=\frac{k_{2} q_{e}^{2}}{1+k_{2} q_{e} t} t
$$

As mentioned before, $q_{t}$ and $q_{e}$ are the metal uptake capacity (mg gG) at any time $t$ and at equilibrium. Azizian [26] also reported that $k_{2}(\mathrm{~g} \mathrm{mgG} \mathrm{minG})$ is the observed rate constant of the pseudo-second-order model which is a complex function of the initial concentration of solute. Linearized form of Eq. (12) is determined as,

$$
\frac{t}{q_{t}}=\frac{1}{k_{2} q_{e}{ }^{2}}+\frac{1}{q_{e}} t
$$

The plot of $t / q_{t}$ as a function of $t$ yields a straight line from which $k_{2}$ and $q_{e}$ are calculated. Fig. 3. shows two forms of pseudo-second-order kinetic model.

From Table 3, it can be observed that the calculated kinetic parameters and their corresponding $R^{2}$ values do not vary for the two forms of the pseudo-second-order kinetic model. But it should be noted that different linear forms of the same model would significantly effect on obtained values of parameters, for example Yuh-Shan Ho [29] examined four linear forms of pseudo-second-order equations to fit the kinetic sorption data. As a result using linear regression method is not appropriate for comparing the best-fitting and Non-linear method is a better way to find the kinetic parameters.

From Table 2 and Table 3, high correlation coefficients $\left(\mathrm{R}^{2}\right)$ of non-linearized form of two models show that both of them can well describe experimental data. However, the difference between the experimental adsorption capacity of $\mathrm{Fe}(\mathrm{II})$ and the value predicted from the pseudo-first-order model was considerably lower than 
Table 3: Pseudo-second-order kinetic parameters for Fe(II) ions adsorption by chitosan

\begin{tabular}{|c|c|c|c|c|c|c|c|}
\hline \multirow[b]{2}{*}{$\mathrm{C}_{0}(\mathrm{mg} \mathrm{1G})$} & \multirow[b]{2}{*}{$\mathrm{q}_{\mathrm{e}, \mathrm{exp}}(\mathrm{mg} \mathrm{gG})$} & \multicolumn{3}{|l|}{ Linear form } & \multicolumn{3}{|c|}{ Non-linear form } \\
\hline & & $\mathrm{q}_{\mathrm{e}}(\mathrm{mg} \mathrm{gG})$ & $\mathrm{k}_{2}(\mathrm{gmgG} \min G)$ & $\mathrm{R}^{2}$ & $\mathrm{q}_{\mathrm{e}}(\mathrm{mg} \mathrm{gG})$ & $\mathrm{k}_{2}(\mathrm{gmgG} \min G)$ & $\mathrm{R}^{2}$ \\
\hline 10 & 6.39 & 7.022472 & 0.008339 & 0.9992 & 7.265233 & 0.00768 & 0.9952 \\
\hline 15 & 9.43 & 11.31222 & 0.003478 & 0.9933 & 11.69863 & 0.00312 & 0.9873 \\
\hline 20 & 12.41 & 15.01502 & 0.002500 & 0.9946 & 15.49422 & 0.002233 & 0.9903 \\
\hline 25 & 15.59 & 17.69912 & 0.002512 & 0.9967 & 18.13636 & 0.002305 & 0.9849 \\
\hline 30 & 18.64 & 22.42152 & 0.001273 & 0.9943 & 23.02214 & 0.001177 & 0.9856 \\
\hline 35 & 20.9 & 26.73797 & 0.000732 & 0.9807 & 27.26519 & 0.000664 & 0.9766 \\
\hline 40 & 24.51 & 28.32861 & 0.001268 & 0.9974 & 28.85714 & 0.001164 & 0.9917 \\
\hline 45 & 27.4 & 33.89831 & 0.000693 & 0.9936 & 34.14108 & 0.000706 & 0.9916 \\
\hline 50 & 28.71 & 39.68254 & 0.000338 & 0.9783 & 38.40397 & 0.000393 & 0.9943 \\
\hline
\end{tabular}
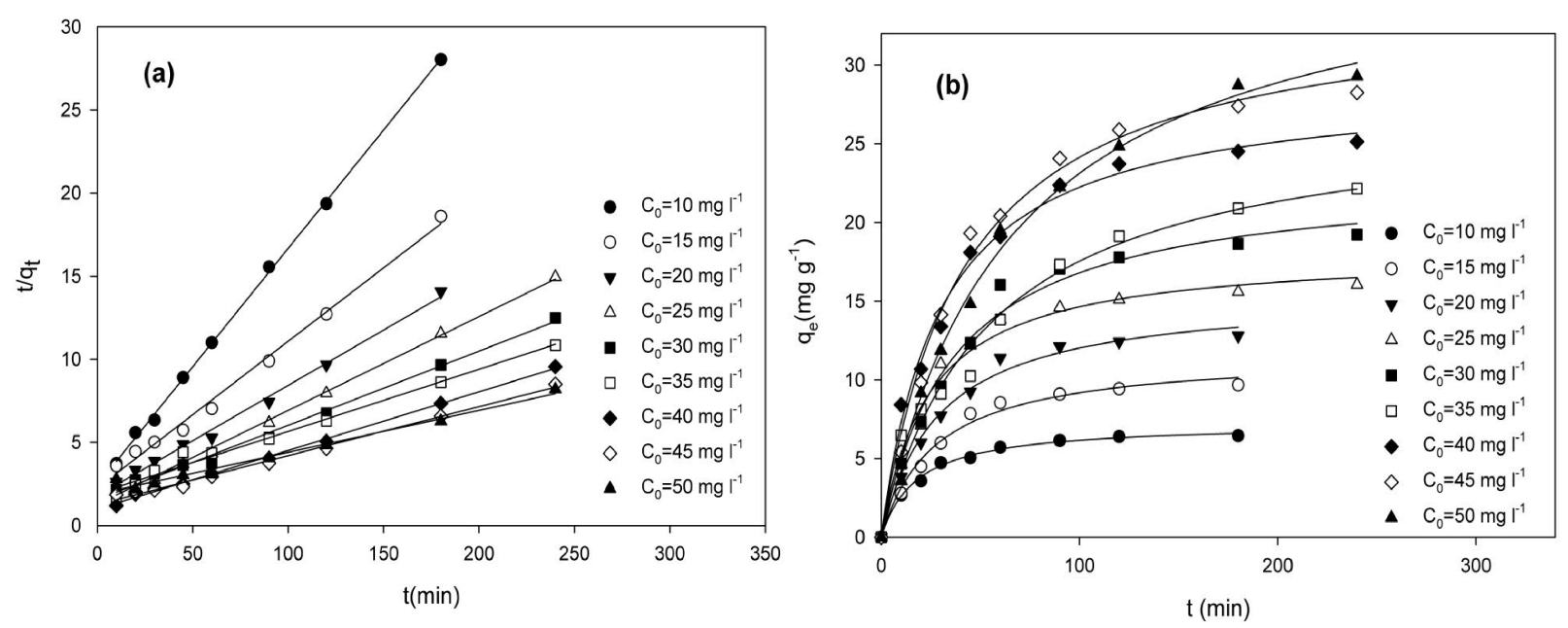

Fig. 3: Pseudo-second-order kinetic model of Fe(II) adsorption on chitosan, (a) linear and (b) non-linear form.

those predicted by the pseudo-second-order. Hence, in this study the non-linearized form of pseudofirst-order model can be considered as a more suitable kinetic model to describe $\mathrm{Fe}(\mathrm{II})$ adsorption. So the adsorption of $\mathrm{Fe}$ (II) onto chitosan may take place through a physical process.

Intraparticle Diffusion Model: Since pseudo-first-order and pseudo-second-order equations can not identify the diffusion mechanisms, the intraparticle diffusion model was also tested. Such plots may present a multilinearity, indicating that two or more steps are taking place. The rate determining step of adsorption reaction may be external film diffusion, intraparticle diffusion or interaction step. The first, sharper portion is the external surface sorption or instantaneous sorption stage. The external film diffusion is usually eliminated by stirring. So the adsorption rate may be controlled by other steps. In the second portion which is the gradual sorption stage, intraparticle diffusion controls the rate. The third portion is the final equilibrium stage where intraparticle diffusion

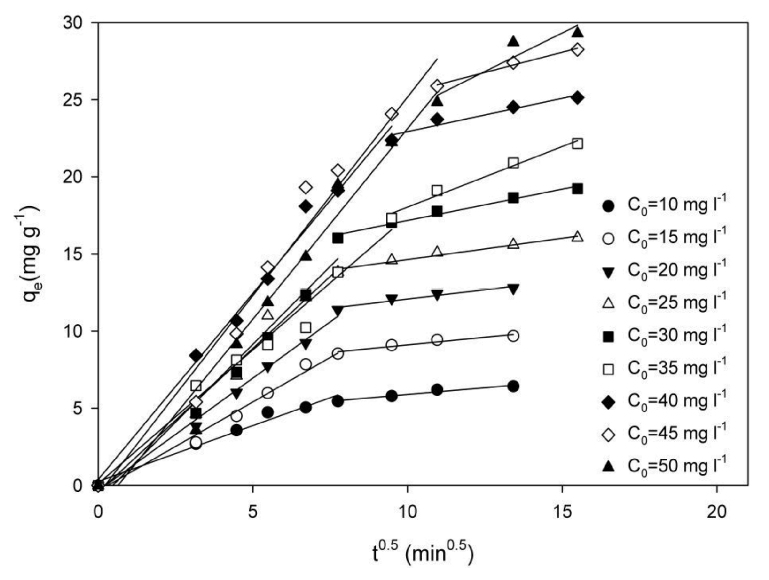

Fig. 4: Intraparticle diffusion kinetic model for the adsorption of $\mathrm{Fe}(\mathrm{II})$ on chitosan.

starts to slow down because of extremely low adsorbate concentrations in the solution. In fact the metal ions are slowly transported via intraparticle diffusion into the particles and are finally retained in micropores [30, 31]. This model is presented as, 
Iranica J. Energy \& Environ., 2 (3): 250-257, 2011

Table 4: Intraparticle diffusion kinetic model parameters for Fe(II) ions adsorption by chitosan

\begin{tabular}{lccc}
\hline $\mathrm{C}_{0}(\mathrm{mg} \mathrm{lG})$ & $\mathrm{k}_{\mathrm{id1}}\left(\mathrm{mg} \mathrm{gGmin}^{-1 / 2}\right)$ & $\mathrm{R}^{2}$ & $\mathrm{k}_{\mathrm{id} 2}\left(\mathrm{mg} \mathrm{gGmin}^{-1 / 2}\right)$ \\
10 & 0.7239 & 0.9745 & 0.1749 \\
15 & 1.1540 & 0.9865 & 0.1985 \\
20 & 1.4593 & 0.9931 & 0.2410 \\
25 & 1.8656 & 0.9777 & 0.2763 \\
30 & 2.0203 & 0.9741 & 0.9290 \\
35 & 1.7365 & 0.9779 & 0.9313 \\
40 & 2.4132 & 0.9893 & 0.9688 \\
45 & 2.5726 & 0.9703 & 0.4319 \\
50 & 2.4703 & 0.9742 & 0.9774 \\
\hline
\end{tabular}

$$
q_{t}=k_{i d} t^{0.5}
$$

Where $k_{i d}$ is the intra-particle diffusion rate constant $\left(\mathrm{mg} \mathrm{gGmin}{ }^{-1 / 2}\right)$.

As Fig. 4. shows, the external surface sorption (stage 1) is absent because of fast completion. All plots have same general features, initial linear portion (stage 2) followed by second linear portion (stage 3 ).

The recovered intraparticle rate constants as well as regression correlation coefficients are presented in Table 4. It is obvious that the intraparticle diffusion model fits the experimental data well for an initial period (stage 2) of the adsorption process with respect to higher correlation coefficient.

\section{CONCLUSION}

Removal of $\mathrm{Fe}(\mathrm{II})$ from aqueous solution by adsorption onto chitosan adsorbent was carried out at a constant temperature. Equilibrium studies revealed that Langmuir-Freundlich hybrid isotherm can describe equilibrium data better than Langmuir and Freundlich models. Linear and non-linear forms of pseudo-first and pseudo-second-order kinetic models were applied to fit the kinetic data. It cab be concluded that non-linear forms of kinetic models are more acceptable with respect to higher correlation coefficients. Finally results showed that metal uptake capacity values predicted by non-linearezed form of pseudo-first-order kinetic model was closer to experimental ones. As well intra-particle diffusion model was applied to identify the mechanism of transport. The results demonstrated that pore diffusion and surface diffusion occur in parallel within chitosan particles during adsorption.

\section{Nomenclature:}

$b \quad$ Langmuir-Freundlich isotherm constant

$C_{0} \quad$ Initial metal concentrations ( $\left.\mathrm{mg} \mathrm{lG}\right)$

$C_{e} \quad$ Equilibrium metal concentrations (mg 1G) $k_{1} \quad$ Observed rate constant of pseudo-first-order kinetic model $(\min G)$

$k_{2} \quad$ Observed rate constant of pseudo-second-order kinetic model ( $\mathrm{g}$ mgGminG)

$k_{a} \quad$ Adsorption rate constant

$k_{d} \quad$ Desorption rate constant

$k_{F} \quad$ Freundlich equilibrium constant $\left(\mathrm{mg} \mathrm{gG}(1 \mathrm{mgG})^{1 / \mathrm{n}}\right)$

$k_{i d} \quad$ intra-particle diffusion rate constant $\left(\mathrm{mg} \mathrm{gGmin}^{-1 / 2}\right)$

$k_{L} \quad$ Langmuir equilibrium constant ( $\left.1 \mathrm{mgG}\right)$

$k_{L . F} \quad$ Langmuir-Freundlich equilibrium constant (1 mgG)

$m \quad$ Mass of used adsorbent (g)

$n \quad$ Freundlich isotherm constant

$q_{e} \quad$ metal uptake capacity at equilibrium ( $\mathrm{mg} \mathrm{gG}$ )

$q_{\text {exp }}$ experimental value of adsorption capacity at equilibrium (mg gG)

$q_{m} \quad$ Maximum uptake capacity obtained by models (mg gG)

$q_{t} \quad$ Metal uptake capacity at any time $\mathrm{t}(\mathrm{mg} \mathrm{gG})$

$R_{L} \quad$ Separation factor

$R^{2} \quad$ Correlation coefficient

$V_{0} \quad$ Initial volume of the solution (1)

$V_{e} \quad$ Final volume of the solution (1)

$t \quad$ Time (min)

$T \quad$ Solution temperature $\left({ }^{\circ} \mathrm{C}\right)$

\section{REFERENCES}

1. Paulino, A.T., L.B. Santos and J. Nozaki, 2008. Removal of $\mathrm{Pb}^{2+}, \mathrm{Cu}^{2+}$, and $\mathrm{Fe}^{3+}$ from battery manufacture wastewater by chitosan produced from silkworm chrysalides as a low-cost adsorbent. React. Funct. Polym., 68(2): 634-642.

2. Hernandez, R.1.B., A.P. Franco, O.R. Yola, A. LópezDelgado, J. Felcman, M.A.L. Recio and A.L.R. Mercê, 2008. Coordination study of chitosan and $\mathrm{Fe}^{3+}$. J. Mol. Struct. 877(1-3): 89-99.

3. Vasudevan, S., J. Lakshmi and G. Sozhan, 2009. Studies on the Removal of Iron from Drinking Water by Electrocoagulation-A Clean Process. CLEAN-Soil, Air, Water 37(1): 45-51. 
4. Lasanta, C., I. Caro and L. Pérez, 2005. Theoretical model for ion exchange of iron (III) in chelating resins: Application to metal ion removal from wine. Chem. Eng. Sci. 60(13): 3477-3486.

5. Nurmi, P., B. Ozkaya, K. Sasaki, A.H. Kaksonen, M. Riekkola-Vanhanen, O.H. Tuovinen and J.A. Puhakka, 2011. Biooxidation and precipitation for iron and sulfate removal from heap bioleaching effluent streams. Hydrometallurgy, 101(1-2): 7-14.

6. Li, M., Z. He and L. Zhou, 2011. Removal of iron from industrial grade aluminum sulfate by primary amine extraction system. Hydrometallurgy, 106(3-4): 170-174.

7. Bernat, X., A. Pihlajamäki, A. Fortuny, C. Bengoa, F. Stüber, A. Fabregat, M. Nyström and J. Font, 2009. Non-enhanced ultrafiltration of iron(III) with commercial ceramic membranes. J. Membr. Sci., 334(1-2): 129-137.

8. Tahir, S. and N. Rauf, 2004. Removal of Fe (II) from the wastewater of a galvanized pipe manufacturing industry by adsorption onto bentonite clay. J. Environ. Manage. 73(4): 285-292.

9. Ren, Y., X. Wei and M. Zhang, 2008. Adsorption character for removal $\mathrm{Cu}$ (II) by magnetic $\mathrm{Cu}$ (II) ion imprinted composite adsorbent. J. Hazard. Mater. 158(1): 14-22.

10. Fernandes, A.N., C.A.P. Almeida, N.A. Debacher and M.M.d.S. Sierra, 2010. Isotherm and thermodynamic data of adsorption of methylene blue from aqueous solution onto peat. J. Mol. Struct. 982(1-3): 62-65.

11. Mohan, D. and C.U. Pittman, 2007. Arsenic removal from water/wastewater using adsorbents--A critical review. J. Hazardous Materials, 142(1-2): 1-53.

12. Sud, D., G. Mahajan and M. Kaur, 2008. Agricultural waste material as potential adsorbent for sequestering heavy metal ions from aqueous solutions-A review. Bioresource Technol., 99(14): 6017-6027.

13. Varma, A.J., S.V. Deshpande and J.F. Kennedy, 2004. Metal complexation by chitosan and its derivatives: a review. Carbohydr. Polym. 55(1): 77-93.

14. Babel, S. and T.A. Kurniawan, 2003. Low-cost adsorbents for heavy metals uptake from contaminated water: a review. J. Hazard. Mater., 97(1-3): 219-243.

15. Gang, D.D., B. Deng and L.S. Lin, 2010. As (III) removal using an iron-impregnated chitosan sorbent. J. Hazard. Mater., 182(1-3): 156-161.

16. Shafaei, A., F.Z. Ashtiani and T. Kaghazchi, 2007. Equilibrium studies of the sorption of $\mathrm{Hg}$ (II) ions onto chitosan. Chem. Eng. J., 133(1-3): 311-316.
17. Repo, E., J.K. Warchol, T.A. Kurniawan and M.E.T. Sillanpaa, 2010. Adsorption of Co (II) and Ni (II) by EDTA-and/or DTPA-modified chitosan: Kinetic and equilibrium modeling. Chem. Eng. J., 161(1-2): 73-82.

18. Karamanev, D., L. Nikolov and V. Mamatarkova, 2002. Rapid simultaneous quantitative determination of ferric and ferrous ions in drainage waters and similar solutions. Miner. Eng., 15(5): 341-346.

19. Jeon, C. and K. Ha Park, 2005. Adsorption and desorption characteristics of mercury (II) ions using aminated chitosan bead. Water Res., 39(16): 3938-3944.

20. Crini, G. and P. Badot, 2008. Application of chitosan, a natural aminopolysaccharide, for dye removal from aqueous solutions by adsorption processes using batch studies: a review of recent literature. Prog. Polym. Sci., 33(4): 399-447.

21. Ghorbani, F., H. Younesi, S. Ghasempouri, A. Zinatizadeh, M. Amini, and A. Daneshi, 2008. Application of response surface methodology for optimization of cadmium biosorption in an aqueous solution by Saccharomyces cerevisiae. Chem. Eng. J. 145(2): 267-275.

22. Yang, Y.H., T.T. Wu, S.Y. Suen and S.C. Lin, 2011. Equilibrium adsorption of poly(His)tagged proteins on immobilized metal affinity chromatographic adsorbents. Biochem. Eng. J., 54(1): 1-9.

23. Wong, K., C. Lee, K. Low and M. Haron, 2003. Removal of $\mathrm{Cu}$ and $\mathrm{Pb}$ by tartaric acid modified rice husk from aqueous solutions. Chemosphere, 50(1): 23-28.

24. Low, K., C. Lee and S. Liew, 2000. Sorption of cadmium and lead from aqueous solutions by spent grain. Process Biochem., 36(1-2): 59-64.

25. Ho, Y. and G. McKay, 1999. Pseudo-second order model for sorption processes. Process Biochem., 34(5): 451-465.

26. Azizian, S., 2004. Kinetic models of sorption: a theoretical analysis. J. Colloid Interface Sci., 276(1): 47-52.

27. Ahamad, K. and M. Jawed, 2010. Kinetics, equilibrium and breakthrough studies for $\mathrm{Fe}$ (II) removal by wooden charcoal: A low-cost adsorbent. Desalination 251(1-3): 137-145.

28. Kumar, P. and K. Kirthika, 2009. Equilibrium and kinetic study of adsorption of nickel from aqueous solution onto bael tree leaf powder. J. Engineering Sci. and Technol., 4(4): 351-363. 
29. Ho, Y.S., 2006. Second-order kinetic model for the sorption of cadmium onto tree fern: A comparison of linear and non-linear methods. Water Res., 40: 119-125.

30. Monier, M., D. Ayad, Y. Wei and A. Sarhan, 2010. Adsorption of $\mathrm{Cu}$ (II), Co (II), and Ni (II) ions by modified magnetic chitosan chelating resin. J. Hazard. Mater., 177(1-3): 962-970.
31. Ozacar, M. and I. Sengil, 2004. Application of kinetic models to the sorption of disperse dyes onto alunite. Colloids Surf. Physicochem. Eng. Aspects, 242(1-3): 105-113. 